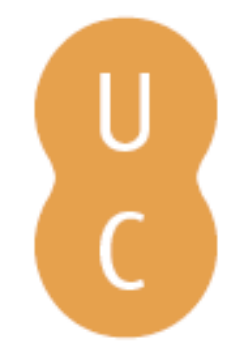

\title{
pommalina
}

\section{Los "combatientes terroristas extranjeros": una nueva amenaza para el orden internacional contemporáneo}

\author{
Autor(es): $\quad$ Cocchini, Andrea \\ Publicado por: Imprensa da Universidade de Coimbra \\ URL \\ persistente: URI:http://hdl.handle.net/10316.2/47441 \\ DOI: $\quad$ DOI:https://doi.org/10.14195/978-989-26-1524-0_17 \\ Accessed : $\quad$ 26-Apr-2023 08:43:27
}

A navegação consulta e descarregamento dos títulos inseridos nas Bibliotecas Digitais UC Digitalis, UC Pombalina e UC Impactum, pressupõem a aceitação plena e sem reservas dos Termos e Condições de Uso destas Bibliotecas Digitais, disponíveis em https://digitalis.uc.pt/pt-pt/termos.

Conforme exposto nos referidos Termos e Condições de Uso, o descarregamento de títulos de acesso restrito requer uma licença válida de autorização devendo o utilizador aceder ao(s) documento(s) a partir de um endereço de IP da instituição detentora da supramencionada licença.

Ao utilizador é apenas permitido o descarregamento para uso pessoal, pelo que o emprego do(s) título(s) descarregado(s) para outro fim, designadamente comercial, carece de autorização do respetivo autor ou editor da obra.

Na medida em que todas as obras da UC Digitalis se encontram protegidas pelo Código do Direito de Autor e Direitos Conexos e demais legislação aplicável, toda a cópia, parcial ou total, deste documento, nos casos em que é legalmente admitida, deverá conter ou fazer-se acompanhar por este aviso.

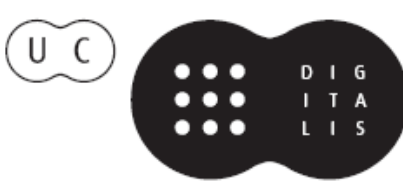


JOSÉ MANUEL PUREZA JOSÉ JUSTE RUIZ (COORDS.)
IMPRENSA DA

UNIVERSIDADE

DE COIMBRA

COIMBRA

UNIVERSITY

PRESS
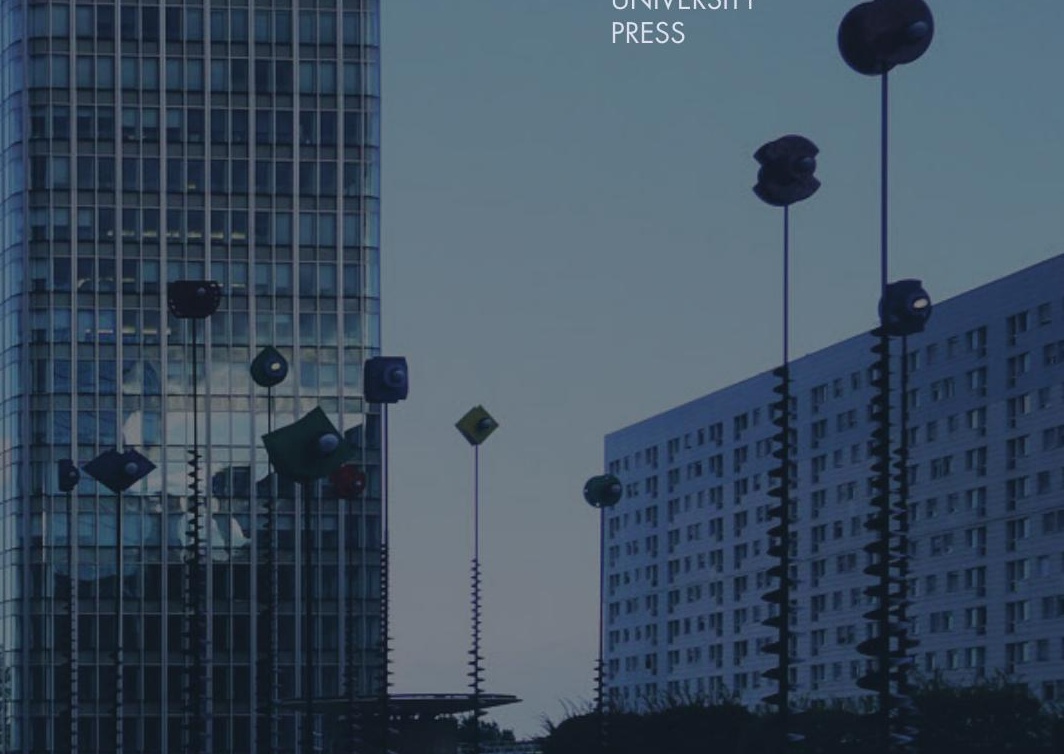

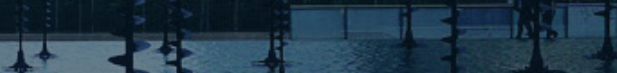

OS ESTADOS

EA ORDEM

INTERNACIONAL

CONTEMPORANEA

ATAS DO V ENCONTRO LUSO-ESPANHOL DE Professores de Direito internacional e RELAÇÕES INTERNACIONAIS 
LOS “COMBATIENTES TERRORISTAS EXTRANJEROS" : UNA NUEVA AMENAZA PARA EL ORDENINTERNACIONAL CONTEMPORÁNEO

\section{Andrea Cocchini}

\section{Un producto del terrorismo yihadista: los denominados "combatientes terroristas extranjeros"}

En los últimos dos años, aproximadamente, hemos asistido al auge de siglas terroristas como la del Estado Islámico (EIIL) y el Frente Al-Nusra 2 (FAN) en Siria e Iraq, Al-Shabaab en Somalia, Boko Haram en Nigeria y de otras organizaciones (Echeverría Jesús, 2014a-b). Esto ha determinado que volviera a tener relevancia la noción de "combatiente extranjero". En efecto, el hecho de que algunos individuos deciden dejar sus hogares para combatir un conflicto armado en el extranjero no es del todo nuevo. Sin ir más lejos, este fenómeno se dio también durante la guerra civil española. El combatiente extranjero puede definirse como «un sujeto que abandona su país de origen o residencia habitual para unirse a un grupo armado no estatal en un conflicto armado en el extranjero y que está principalmente motivado por la ideología, la religión y/o la afinidad" a los ideales yihadistas (Academia de Ginebra de Derecho Internacional Humanitario y Derechos Humanos, 2014: p. 6). Aunque la perspectiva de una remuneración puede representar una motivación ulterior (A/ HRC/28/28, Informe del Alto Comisionado de las Naciones Unidas para 
los Derechos Humanos sobre la protección de los derechos humanos y las libertades fundamentales en la lucha contra el terrorismo, 19 de diciembre de 2014: p. 13, nota 22). No obstante, el combatiente extranjero tiene que mantenerse separado de la categoría de los mercenarios, porque éstos participan en los conflictos armados sustancialmente por razones económicas. El artículo 47 del Protocolo Adicional I (1977) a los cuatros Convenios de Ginebra de 1949 es claro a este respecto:

Se entiende por mercenario toda persona: [...] que tome parte en las hostilidades animada esencialmente por el deseo de obtener un provecho personal y a la que se haga efectivamente la promesa, por un Parte en conflicto o en nombre de ella, de una retribución material considerablemente superior a la prometida o abonada a los combatientes de grado y funciones similares a las fuerzas armadas de esa Parte. (Artículo 47, párrafo 2.C).

De lo que se desprende a contrario que los combatientes extranjeros tienen derecho al estatuto de combatiente o de prisionero de guerra y que se les pueden aplicar las normas del Derecho internacional humanitario. Por otra parte, esto conlleva la consecuencia de que tales combatientes pueden ser susceptibles de enjuiciamiento y sanción por crímenes de guerra (Academia de Ginebra de Derecho Internacional Humanitario y Derechos Humanos, 2014: p. 24).

Ahora bien, una amenaza actual para el orden internacional contemporáneo proviene de una nueva categoría de combatiente extranjero, el denominado "combatiente terrorista extranjero" ( $f_{o}$ reign terrorist fighter). Con esta expresión se quieren indicar todos aquellos milicianos yihadistas reclutados en, y provenientes de, otros Estados que van a engrosar las filas de las organizaciones terroristas. El fenómeno es especialmente masivo en relación al grupo terrorista Estado Islámico. De hecho, se estima que, actualmente, son alrede- 
dor de 21.000 los combatientes extranjeros en Iraq y Siria, de los cuales cerca de 4.000 provienen de Europa occidental (García-Calvo, 2015: p. 2). Como es de esperarse, los Estados que más combatientes extranjeros engendran, en términos absolutos, son también los más populosos; en orden decreciente: Francia, Alemania y Reino Unido. Sin embargo, llama la atención que, en términos relativos, son Bélgica, Dinamarca y Suecia los países que más sufren de este fenómeno. Otro dato a destacar, sobre el cual merecería reflexionar más, es que, a nivel global, es Túnez el Estado que más combatientes extranjeros exporta. Para el país norteafricano se habla de entre 1.500 y 3.000 sujetos que, desde el comienzo de la guerra civil en Siria, han alcanzado las líneas de conflicto. Todo ello pese a que Túnez sea el único Estado en donde el movimiento de levantamiento popular llamado "Primavera árabe» parece haber tenido éxito, llevando a un proceso de democratización del país (Neumann, 2015).

En cuanto a España, ascienden a unos centenares los ciudadanos españoles partidos para las zonas de guerra de Oriente Medio ( $E l$ Mundo, 23 de abril de 2015). Mientras que en relación con Portugal, se habla de apenas una docena de individuos de nacionalidad portuguesa (Ribeiro, 2014). Pese a que a nivel numérico la tendencia no sea especialmente alarmante, en España, como en otros países europeos, hemos asistido a una transformación en las características sociales del terrorismo de matriz yihadista. A partir del año 2013, ocho de cada diez detenidos en España, acusados de formar parte de las redes de reclutamiento yihadistas, eran españoles de nacimiento. Se manifiesta así una significativa inversión de tendencia con respecto a los quince años precedentes, en los que apenas el $5 \%$ de los condenados por reatos relativos al terrorismo fundamentalista habían nacido en España. En otros términos, la amenaza del terrorismo internacional parece estar reconfigurándose, adquiriendo los semblantes de un tipo de terrorismo, por así decirlo, "hecho en casa». Como señala el Profesor Reinares: "Entre 1996 y 2012, sólo 
el $16,6 \%$ del total de individuos condenados o muertos en nuestro país por actividades relacionadas con el terrorismo yahidista eran de nacionalidad española. Pero en un $11,5 \%$ de los casos se trataba de individuos nacidos en el extranjero y luego naturalizados, mientras que sólo un 5,1\% había nacido en España." (Reinares, 2014)

Sin raíces en la tierra de sus antepasados y sin haberlas aún consolidadas en el Estado de nacimiento y de formación, los jóvenes son más susceptibles al mensaje del yihad internacional, que les proporciona esa identidad de guerrero en nombre de una cierta lectura del mensaje coránico (Barker, 2014: pp. 10-12; Cronin, 2015: p. 94; Reinares, 2015). Uno de los elementos de mayor preocupación que deriva del desafío yihadista, íntimamente relacionado con los combatientes terroristas extranjeros, está representado por el fenómeno del "yihadismo de retorno». Estudios recientes estiman que entre un 10 y $30 \%$ de los combatientes terroristas extranjeros ya ha dejado las zonas de combate, verosímilmente para volver a sus Estados de origen (Neumann, 2015). El peligro es que estas personas, que regresan a sus países bien adiestrados, lleven a cabo atentados en forma individual u organizada, o preparen nuevos aspirantes combatientes (Strategic Comments, 2014: pp. x-xi). Basta con mencionar tres de los casos más recientes acontecidos en Europa occidental. En primer lugar, el atentado antisemita al Museo judío de Bruselas de 24 de mayo de 2014 que mató a cuatro personas. En segundo lugar, el tiroteo en la redacción del periódico satírico Charlie Hebdo en Paris el 7 de enero de 2015, que causó la muerte de once personas. El último ejemplo en orden de tiempo es el de los ataques múltiples, en distintas áreas de Paris, de 13 de noviembre de 2015, que cobraron las vidas de más de ciento y treinta personas. Los detalles de estos acontecimientos son notos a todos, por lo que no hace falta profundizarlos aquí. Lo único que es importante resaltar es que todos estos atentados tienen en común que fueron perpetrados por combatientes retornados de Siria y de Yemen con ciudadanía francesa y belga. 


\section{Las soluciones avanzadas por el Consejo de Seguridad de las Naciones Unidas y los interrogantes que suscitan}

Ante este panorama, el Consejo de Seguridad de las Naciones Unidas aprobó, ante todo, la resolución 2170 (2014). En su preámbulo, el Consejo define el Estado Islámico, el Frente Al-Nusra y las demás siglas relacionadas con Al-Qaeda como "una amenaza para la paz y la seguridad internacionales»(S/RES/2170, 15 de agosto de 2014, preámbulo, párr. 18). Expresa, asimismo, su preocupación por:

[L]a afluencia de combatientes terroristas extranjeros a las filas del EIIL, el FAN y demás personas, grupos, empresas y entidades asociados con Al-Qaida, y por la magnitud de este fenómeno. (S/ RES/2170, 15 de agosto de 2014, preámbulo, párr. 12)

Entonces, dedica a los combatientes terroristas extranjeros un apartado entero, en virtud del Capítulo VII de la Carta. En ello, se condena el reclutamiento por las formaciones terroristas de los aspirantes milicianos extranjeros, subrayando que su presencia exacerba los conflictos armados (S/RES/2170, 15 de agosto de 2014, parte dispositiva, párr. 7). Se recuerda también la obligación de todos los Estados miembros de impedir la circulación de terroristas, armamentos y fondos financieros, a través de controles fronterizos eficaces y el pronto intercambio de información (S/RES/2170, 15 de agosto de 2014, parte dispositiva, párr. 8). Y a este propósito, el Consejo invita los Estados a mejorar la cooperación entre las autoridades nacionales para frenar el tránsito de los terroristas hacia y desde sus territorios, así como el tráfico de armas y otros pertrechos militares (S/RES/2170, 15 de agosto de 2014, parte dispositiva, párr. 10).

Van en esta dirección también muchas de las previsiones de la sucesiva resolución 2178 (2014), objeto principal de esta breve contribución. Adoptada bajo el Capítulo VII de la Carta, la resolución intenta prevenir y combatir de manera global el creciente "turismo yahidista del terror»(Ambos, 2014): el reclutamiento y el traslado 
de aspirantes yihadistas a los territorios de combate. En ella, el Consejo de Seguridad se ocupa detenidamente de los combatientes terroristas extranjeros, que define como:

[L]as personas que viajan a un Estado distinto de su Estado de residencia o nacionalidad con el propósito de cometer, planificar o preparar actos terroristas o participar en ellos, o de proporcionar o recibir adiestramiento con fines de terrorismo, incluso en relación con conflictos armados. (S/RES/2178, 24 de septiembre de 2014, preámbulo, párr. 8)

Subraya así que tales sujetos constituyen «una seria amenaza para sus Estados de origen, los Estados por los cuales transitan y los Estados a los que viajan, así como para los Estados vecinos de las zonas de conflicto armado", en las que estos individuos ejecutan sus acciones (S/RES/2178, 24 de septiembre de 2014, preámbulo, párr. 10).

En su parte dispositiva, la resolución 2178 (2014), de carácter casi-legislativo al estilo de la conocida resolución 1373 (2001), prevé toda una serie de medidas dirigidas a frenar esta nueva amenaza (Milanovic, 2014). Así, a modo de ejemplo, el Consejo de Seguridad:

[E]xige que todos los combatientes terroristas extranjeros depongan las armas, pongan fin a todos los actos terroristas y dejen de participar en los conflictos armados. (S/RES/2178, 24 de septiembre de 2014, parte dispositiva, párr. 1)

Además, insta a los Estados que:

[A]gilicen el intercambio de información operacional sobre las actividades o los movimientos de [...] los combatientes terroristas extranjeros, especialmente con sus Estados de residencia o nacionalidad, por medio de mecanismos bilaterales o multilaterales, en particular, las Naciones Unidas. (S/RES/2178, 24 de septiembre de 2014, parte dispositiva, párr. 3) 
Sin embargo, entre las numerosas medidas adoptadas en la resolución, es interesante destacar la que impone a todos los Estados Miembros que:

[I]mpidan la entrada en su territorio o el tránsito por él de toda persona sobre la cual ese Estado tenga información fidedigna que ofrezca motivos razonables para creer que está tratando de entrar en su territorio, o transitar por él, con el propósito de participar en los actos [de terrorismo]. (S/RES/2178, 24 de septiembre de 2014, parte dispositiva, párr. 8)

Leyendo esta previsión, surge espontanea una pregunta: ¿cómo identificar las intenciones terroristas del individuo que sale de un Estado para dirigirse hacia otro y de ahí trasladarse a los territorios de combate? El Consejo de Seguridad exhorta a los Estados a que, en la evaluación del riesgo y en el control de las fronteras, no se dejen guiar por "perfiles basados en estereotipos que obedecen a motivos de discriminación prohibidos por el derecho internacional” (S/RES/2178, 24 de septiembre de 2014, parte dispositiva, párr. 3). Ahora bien, ¿cómo puede - concretamente - un oficial de frontera suponer las intenciones criminosas de un sujeto, sino en base a ciertas características externas (vestimenta, aspecto físico, contenido de su equipaje)? En definitiva: ¿sin dejarse guiar, más o menos voluntariamente, por una cierta discriminación racial-religiosa? (Ambos, 2014)

Francamente, algunas de las medidas propuestas por el Consejo de Seguridad en esta resolución, como las mencionadas, son bastante nubosas y de difícil aplicación concreta. Manifiestan, una y otra vez, las dificultades de este órgano para proporcionar una respuesta efectiva ante a una nueva amenaza para el orden internacional contemporáneo. Estas previsiones son la demostración de que la comunidad internacional, a través de su máximo representante, las Naciones Unidas, está buscando algún remedio para taponar el derramamiento 
de sangre. Sin embargo, no parece tener una estrategia concreta y detallada. Del mismo modo, aquellas medidas vislumbran posibles problemas de protección de los derechos humanos fundamentales: libertad de movimiento, derecho de pedir asilo político, derecho de volver al país de nacionalidad, etc. La incorporación del calificativo "terrorista" a la expresión "combatiente extranjero", junto a la falta de una definición internacional de "terrorismo" es, tal vez, una de las causas principales de esas dificultades. Y esto porque la ausencia de una noción precisa de "terrorismo" deja cada Estado libre de evaluar quién es un terrorista y quién no lo es, con todas las consecuencias que esto implica (Conte, 2015). Es más, la resolución 2178 (2014) se refiere al "terrorismo en todas sus formas y manifestaciones" ( $\mathrm{S}$ / RES/2178, 24 de septiembre de 2014, preámbulo, párr. 1), y no sólo al terrorismo transnacional, como una de las peores amenazas para la seguridad internacional. Esta locución no es sin consecuencias, porque puede motivar los Estados a un endurecimiento de la legislación doméstica, más allá los objetivos que la resolución quiere alcanzar (Milanovic, 2014).

Lo que está pasando en Europa nos muestra que, en los que deciden convertirse en combatientes terroristas, falta la asimilación de la cultura propia de la sociedad en las que han nacido y se han desarrollado. No se puede analizar en esta sede la miríada de razones que residen detrás de ello y tampoco tiene relevancia directa para el presente artículo. No obstante, desde esta perspectiva, otro elemento a tener en cuenta, cuando se habla de estos combatientes terroristas extranjeros, es la novedad introducida por el Estado Islámico en los métodos de reclutamiento de las nuevas levas. Las largas reprimendas lanzadas a Occidente por Bin Laden y grabadas en VHS, no tienen nada que ver comparadas con los videos propagandísticos del Estado Islámico. Esta organización sabe manejar muy hábilmente el instrumento de la propaganda a través de la red; retrasmitiendo grabaciones aterradoras dignas de Hollywood, 
si no mostraran la cruda realidad de la barbarie que está llevando a cabo. A este propósito, cabe una pequeña digresión. Parece ser que detrás de las imágenes espeluznantes de las decapitaciones del miliciano conocido como "Jihadi John» esté un angolano con nacionalidad portuguesa, Nero Saraiva. Éste sería el cabecilla de un grupo de yihadistas originarios de las antiguas colonias africanas de Portugal (Chacón, 2015). En particular, la difusión de las redes sociales, como Facebook y Twitter, representa un amplificador potentísimo del mensaje yihadista entre los más jóvenes. En este sentido, es significativo que el Consejo de Seguridad manifieste su inquietud frente al progresivo recurso por los terroristas a:

[L]as tecnologías de las comunicaciones, en particular Internet, con fines de radicalización conducente al terrorismo y reclutamiento e incitación a cometer actos terroristas, y para financiar y facilitar los viajes y las actividades posteriores de los combatientes terroristas extranjeros [...]. (S/RES/2178, 24 de septiembre de 2014, parte dispositiva, párr. 15)

\section{Algunas alternativas para frenar la amenaza del terrorismo fundamentalista y de los combatientes terroristas extranjeros}

Frente a la renovada amenaza del terrorismo yihadista, que se manifiesta hoy día también en los atentados perpetrados por los combatientes terroristas extranjeros, la comunidad de Estados ha respondido lanzando la operación Determinación Absoluta. La misión consiste en una campaña sistemática de incursiones aéreas miradas en contra de los emplazamientos del Estado Islámico. La finalidad es la de apoyar a las fuerzas iraquíes y kurdas sobre el terreno, tanto en el frente iraquí como en el frente sirio del conflicto, para degradar y finalmente derrotar la banda terrorista (Statement by the 
President on ISIL, The White House, Office of the Press Secretary, 2014). De modo que nos encontramos, otra vez, ante a una situación en la que se ha preferido intervenir militarmente, en reacción a los atentados y a las atrocidades de los que hemos sido testigos, en cambio de perseverar en la prevención y la cooperación. Sin embargo, a estas alturas, la cura a través de la acción armada podría ser invasiva cuanto inútil, frente a una enfermedad que ya se encuentra en el cuerpo occidental y parece haber irrumpido en su tejido social. Por eso, creo que las propuestas más interesantes elaboradas por el Consejo de Seguridad con la resolución 2178 (2014), se encuentran en la sección dedicada a «la lucha contra el extremismo violento para prevenir el terrorismo"(S/RES/2178, 24 de septiembre de 2014, parte dispositiva, párrs. 15-19). En ella, se insta a los Estados a que busquen la cooperación de las comunidades locales y de las organizaciones no gubernamentales oportunas para elaborar estrategias de contraste a la retórica del extremismo:

[I]ncluso empoderando a los jóvenes, las familias, las mujeres, los líderes religiosos, culturales y de la educación y todo otro grupo interesado de la sociedad civil, y adoptar enfoques específicos para combatir el reclutamiento de personas para este tipo de extremismo violento y promover la inclusión y la cohesión sociales. (S/RES/2178, 24 de septiembre de 2014, parte dispositiva, párr. 16)

El llamamiento al papel de la educación para neutralizar la retórica terrorista es esencial en este contexto. El Consejo de Seguridad destaca:

[L]a importancia de que los Estados Miembros ideen medios alternativos no violentos para la prevención y solución de conflictos por las personas y las comunidades locales afectadas a fin de reducir el riesgo de radicalización con recurso al terrorismo, y 
de que promuevan alternativas pacíficas a la retórica violenta a la que se adhieren los combatientes terroristas extranjeros, y recalca la función que puede desempeñar la educación para contrarrestar las retóricas terroristas. (S/RES/2178, 24 de septiembre de 2014, parte dispositiva, párr. 19)

Debido a las características intrínsecas de la amenaza terrorista para la paz y la seguridad internacionales, puede que el uso de la fuerza no sea siempre la solución más adecuada (Bermejo García y López-Jacoiste Díaz, 2005: p. 9). En términos más generales, pienso que las bombas pueden servir para debilitar a las organizaciones terroristas, pero sus efectos intimidatorios y disuasivos duran sólo a corto plazo. Como muestra Antonio Cassese, la solución coercitiva al terrorismo es atractiva por tener resultados inmediatos: los terroristas vienen capturados o matados antes que puedan perpetrar los atentados y se salvan así vidas inocentes. Pese a ello, la otra cara de la medalla es:

[T]he inescapable fact that violence only begets more violence; thus, the hijack of hijackers becomes, not the end of hijacking, but the beginning of new hijacking. (Cassese, 1989: p. 606) En pocas palabras, el recurso a la acción armada para luchar en contra del terrorismo internacional no es oportuna ni fáctica ni jurídicamente. En efecto, en numerosas resoluciones, el Consejo de Seguridad invirtió sus esfuerzos para elaborar unos mecanismos coercitivos, pero no militares, para repeler la plaga del terrorismo radical. Considerando el periodo inmediatamente sucesivo a los atentados del 11-S, el Consejo de Seguridad aprobó unas resoluciones que fijan unas medidas, obligatorias para todos los Estados, para combatir el terrorismo. La resolución 1368 (2001) condena el terrorismo como amenaza para la paz y la seguridad internacionales (S/RES/1368, 12 de septiembre de 2001, parte dispositiva, párr. 1). La resolución 1373 (2001), con arreglo al Capítulo VII de la Carta, crea un Comité contra 
el Terrorismo e impone a los Estados, entre las demás medidas: la prevención y la supresión de la financiación de actos de terrorismo; la congelación de los recursos económicos de los sujetos vinculados a grupos terroristas; y la cooperación estatal en esta lucha (S/ RES/1373, 28 de septiembre de 2001, parte dispositiva, párrs. 1-3 y 6). Asimismo, la resolución 1377 (2001) insiste en la "comprensión entre las civilizaciones» y en la promoción de prácticas idóneas, programas técnicos, financieros y legislativos para que los Estados rechacen eficazmente el terrorismo (S/RES/1377, 12 de noviembre de 2001, anexo sobre la acción mundial para combatir el terrorismo, pp. 2-3). No nos olvidemos, además, de los doce convenios contra el terrorismo, del Derecho internacional consuetudinario, de los Convenios de Ginebra y del Estatuto de Roma que prohíben todas las formas de terrorismo (A/59/565 (2004), Un mundo más seguro: la responsabilidad que compartimos, Informe del Grupo de alto nivel sobre las amenazas, los desafíos y el cambio, párr. 159). En este sentido, tiene razón el Profesor Christian Dominicé, cuando afirma que los documentos legales de carácter internacional existentes constituyen un dispositivo jurídico que cubre prácticamente todos los aspectos de la lucha contra el terrorismo internacional. No obstante, subraya que el problema mayor es la puesta en marcha y una cooperación escasa por parte de los Estados para enfrentarse a esta amenaza: "[L] e problème majeur est leur mise en oeuvre par les Etats. Il manque encore de nombreuses ratifications, la volonté de coopérer n'est pas encore suffisante. [...] Une meilleure coopération internationale implique donc la solution de conflits qui font le lit du terrorisme. A ce prix, les Etats verront que qu'ils ont tous intérêt à un front commun contre un phénomène dont chacun peut être victime un jour ou l'autre. (Dominicé, 2013: p. 301, nota 807 y p. 302)".

De tal manera que una mejora decidida de la cooperación entre Estados en materia anti-terrorista es la vía a seguir también para limitar el fenómeno de los combatientes terroristas extranjeros. 
En cambio de apostar por estrategias nacionales individuales y desconectadas una de la otra, los Estados deberían insistir en una estrategia común multilateral. Como ya sugirió la Comisión nacional que investigó los hechos del 11-S (9-11 Commission), sirve volver las estrategias nacionales en estrategias colectivas (The 9/11 Commission Report, 2004: p. 379). Entre las propuestas contenidas en el documento, son destacables las de: seguir la pista del dinero, cortar las fuentes de financiación (The 9/11 Commission Report, 2004: p. 382), y trazar los viajes de los posibles miembros de grupos terroristas:

Targeting travel is at least as powerful a weapon against terrorists as targeting their money. [...] We should do more to exchange terrorist information with trusted allies, and raise U.S. and global border security standards for travel and border crossing over the medium and long term through extensive international cooperation. (The 9/11 Commission Report, 2004: pp. 385 y 390).

Todo ello en el marco de operaciones de policías coordinadas a nivel interestatal (Public Statement Release of 9/11 Commission Report, 2004: p. 3, punto 3).

Por lo tanto, es necesaria una mayor cooperación y coordinación entre Estados miembros en tema de terrorismo internacional y un potenciamiento de la capacidad de los países de Norte de África y de Oriente Medio para encargarse de la propia seguridad (Arteaga, 2014: p. 2). La concertación entre los Estados occidentales y medio-orientales es fundamental para eliminar las condiciones que determinaron la aparición del Estado Islámico y de las demás organizaciones yihadistas (Arteaga, 2014: p. 5). Con lo que se comparte el análisis del Profesor Reinares, que advierte que el reto para el orden internacional contemporáneo es el de "contrarrestar la narrativa del extremismo violento y prevenir los procesos de radicalización yihadista». Pero, sobre todo, "promover identidades 
colectivas democráticas" (Reinares, 2015). Es necesaria, en fin, una evolución del sistema de seguridad colectiva que contemple medidas - de carácter económico, social, político, cultural... - que releguen el uso de la fuerza a último recurso (A/59/565 (2004), Un mundo más seguro: la responsabilidad que compartimos, Informe del Grupo de alto nivel sobre las amenazas, los desafíos y el cambio, párr. 148).

Desde esta perspectiva, en el Documento Final de la Cumbre Mundial 2005, la comunidad internacional celebró el establecimiento por muchos Estados desarrollados del:

[O]bjetivo de destinar el $0,7 \%$ del producto nacional bruto a la asistencia oficial para el desarrollo a más tardar en 2015 y de llegar a dedicar por lo menos el $0,5 \%$ del producto nacional bruto a la asistencia oficial para el desarrollo a más tardar en 2010, así como de destinar del $0,15 \%$ al $0,20 \%$ a los países menos adelantados como máximo en 2010 en cumplimiento del Programa de Acción de Bruselas para los Países Menos Adelantados para el Decenio 2001-2010. (A/RES/60/1 (2005), Documento final de la Cumbre Mundial 2005, párr. 23, b).

Sin embargo, en 2010, el Secretario General informó que el total de la asistencia oficial para el desarrollo (AOD), según las mediciones del Comité de Asistencia para el Desarrollo de la Organización de Cooperación y Desarrollo Económicos (OCDE), era el 0,09\% del ingreso nacional bruto (INB) de los países donantes. Un porcentaje muy por debajo del objetivo de entre el $0,15 \%$ y el $0,20 \%$. A este dato, el Señor Ban añadió que algunos donantes ya habían reducido o aplazado las promesas de donaciones que habían hecho para 2010, dejando así esfumar definitivamente la esperanza de alcanzar el objetivo dentro de aquella fecha (A/65/80 - E/2010/77, 17 de mayo de 2010, Informe del Secretario General a la Asamblea General y al Consejo Económico y Social: Ejecución del Programa de Acción en 
favor de los países menos adelantados para el decenio 2001-2010, párr. 91). También los últimos datos disponibles muestran que, en 2014, la asistencia oficial para el desarrollo total de los Estados miembros del Comité de Asistencia para el Desarrollo (CAD) representó el 0,29\% de su ingreso nacional bruto (INB). Sólo Dinamarca, Luxemburgo, Noruega, Reino Unido y Suecia permanecieron por encima del objetivo de la asistencia oficial para el desarrollo de 0,7\% del INB fijado por las Naciones Unidas (Objetivos de Desarrollo del Milenio: Informe de 2015, pp. 62-63).

Es importante recordar en estos momentos los objetivos que los Estados se empeñaron en cumplir hace ya diez años. Y esto porque aquellas medidas, si realmente realizadas, hubiesen representado la vía más eficaz para derrotar al terrorismo internacional, que se alimenta de la pobreza y de la ignorancia de la gente. Como apunta Whitman, la eficacia del Derecho internacional no se mide en la alacridad con la que se ejecuta, sino en la interiorización, en la íntima aceptación de sus normas por la comunidad internacional (Whitman, 2005: p. 270). Invertir en el desarrollo significa invertir en educación, la primera cura en contra de la radicalización que lleva al terrorismo.

Ahora bien, las medidas que acabamos de revisar representan todas unas estrategias socio-políticas que considero, a largo plazo, los únicos caminos posibles para desafiar eficazmente el terrorismo internacional. Sin embargo, ya demasiadas veces hemos leído de estas apreciables - cuanto inaplicadas - iniciativas por parte de los Estados Miembros. Por lo tanto, en el inmediato, dada la grave situación que está viviéndose sobre el terreno y el comienzo de la operación Determinación Absoluta, la mejor política a seguir sería la que ha sido definida de "contención ofensiva" (Cronin, 2015: p. 97). Una política que combine una campaña militar limitada, con un mayor esfuerzo económico y diplomático para degradar el Estado Islámico y alinear los intereses de los numerosos países amenazados 
por el grupo terrorista. La amenaza del fundamentalismo yihadista, y el fenómeno correlato de los combatientes terroristas extranjeros, es un problema que afecta a los mayores actores globales, como la Unión Europea, los Estados Unidos, Rusia, Irán, Turquía, Arabia Saudí y otros países del Golfo persa. Por eso, las Grandes Potencias, deberían desarrollar una estrategia diplomática, económica y militar común para garantizar la comunidad internacional de los peligros derivados del terrorismo. Una estrategia que vaya más allá tanto de los acuerdos mutuos para prevenir la radicalización y el reclutamiento de aspirantes yihadistas, cómo de la Coalición de voluntades reunida en torno a los Estados Unidos en la operación Determinación Absoluta. Los Estados Unidos, en particular, en cuanto única superpotencia militar existente, deberían restablecer, en primer lugar, su papel de superpotencia diplomática, antes que militar. Como sugiere la Profesora Cronin:

The major powers and regional players must agree to stiffen the international arms embargo currently imposed on ISIS, enact more vigorous sanctions against the group, conduct joint border patrols, provide more aid for displaced persons and refugees, and strengthen UN peacekeeping missions in countries that border Iraq and Syria. (Cronin, 2015: p. 98).

Gracias a la aplicación de este tipo de medidas, la comunidad internacional daría un paso importante en la lucha al terrorismo internacional y limitaría, a la vez, los flujos de combatientes terroristas extranjeros entre Europa y Oriente Medio.

«Si quieres llegar rápido, camina solo; si quieres llegar lejos, camina acompañado", recita un refrán africano. Pienso que sintetiza bien el enfoque que deberían adoptar los Estados para perseverar en su lucha contra el terrorismo yihadista y los que traen el yihad en nuestro suelo. 


\section{Referencias}

Academia de Ginebra de Derecho Internacional Humanitario y Derechos Humanos (2014), "Foreign Fighters under International Law", Academy Briefing, 7, pp. $1-64$.

Ambos, Kai (2014), "Our terrorists, your terrorists? The United Nations Security Council urges states to combat "foreign terrorist fighters", but does not define "terrorism", EJIL: Talk!, Blog of the European Journal of International Law. Consultado el 23.04.2015, en: http://www.ejiltalk.org/our-terrorists-your-terroriststhe-united-nations-security-council-urges-states-to-combat-foreign-terrorist-fightersbut-does-not-define-terrorism/

Arteaga, Félix (2014a), "The European Union's role in the fight against ISIS", European Leadership Network. Consultado el 29.04.2015, en: http://www. europeanleadershipnetwork.org/the-european-unions-role-in-the-fight-againstisis_1955.html

Arteaga, Félix (2014b), "Oriente Próximo, perdido en el laberinto islamista", Real Instituto Elcano, Opinión, pp. 1-5. Consultado el 09.05.2015, en: http://www.realinstitutoelcano. org/wps/portal/web/rielcano_es/contenido?WCM_GLOBAL_CONTEXT=/elcano/ elcano_es/zonas_es/arteaga-oriente-proximo-perdido-en-el-laberinto-islamista

Ayestarán, Mikel (2010), "Milicias de Al-Sahwa, el "Despertar", Periódico $A B C$ Internacional, de 19 de julio. Consultado el 02.05.2015, en: http://www.abc. es/20100719/internacional/milicias-sahwa-despertar-20100719.html

Barker, Brig (2014), "ISIS: Nothing New Under The Sun", Journal of Counterterrorism \& Homeland Security International, 20(4), pp. 10-12.

Bermejo García, Romualdo, López-Jacoiste Díaz, Eugenia (2005), "Un mundo más seguro: la responsabilidad que compartimos, Informe del Grupo de alto nivel sobre las amenazas, el desafío y el cambio. A modo de introducción", Anuario Español de Derecho Internacional, XXI, pp. 3-12.

Cassese, Antonio (1989), "The International Community's "Legal" Response to Terrorism", International and Comparative Law Quarterly, 38(3), pp. 589-608.

Chacón, Francisco (2015), "Un yihadista portugués, realizador "estrella" de los vídeos de Estado Islámico", Periódico $A B C$, de 6 de febrero. Consultado el 27.04.2015, en: http://www.abc.es/internacional/20150206/abci-yihadista-videoportagula-201502061214.html

Conte, Alex (2015), "An Old Question in a New Context: Do States Have to Comply with Human Rights When Countering the Phenomenon of Foreign Fighters?", EJIL: Talk!, Blog of the European Journal of International Law. Consultado el 21.04.2015, en: http://www.ejiltalk.org/an-old-question-in-a-new-context-do-states-have-tocomply-with-human-rights-when-countering-the-phenomenon-of-foreign-fighters/

Cronin, Audrey Kurth (2015), «ISIS Is Not a Terrorist Group: Why Counterterrorism Won't Stop the Latest Jihadist Threat", Foreign Affairs, 94, pp. 87-98.

Dominicé, Christian (2013), "La société internationale à la recherche de son équilibre", Recueil des Cours de l'Académie de Droit International de la Haye, 370, pp. 29392.

Echeverría Jesús, Carlos (2014a), «El Estado Islámico (EI) como grupo terrorista yihadista salafista y otros grupos armados violentos actuando en Irak hoy", 
Documento de Investigación, 06, Instituto Español de Estudios Estratégicos, pp. 3-15. Consultado el 03.05.2015, en: http://www.ieee.es/Galerias/fichero/docs_ investig/2014/DIEEEINV06-2014_EstadoIslamico_CarlosEcheverria_.pdf

Echeverría Jesús, Carlos (2014b), "Grupos terroristas operando en Siria», Documento de Investigación, 04, Instituto Español de Estudios Estratégicos, pp. 1-14. Consultado el 04.05.2015, en: http://www.ieee.es/Galerias/fichero/docs_investig/2014/ DIEEEINV04-2014_GruposTerroristasOperandoSiria_CEcheverria.pdf

García-Calvo, Carola (2015), "Francia y la profecía autocumplida", Real Instituto Elcano, Opinión, pp. 1-3. Consultado el 05.05.2015, en: http://www.realinstitutoelcano. org/wps/wcm/connect/f337fd8046df8a2ba64ea6005a37fd63/GarciaCalvo-Francia$\mathrm{y}$-la-profecia-autocumplida.pdf?MOD=AJPERES\&CACHEID=f337fd8046df8a2ba64e a6005a37fd63

Guillame, Gilbert (2004), "Terrorism and International Law", International and Comparative Law Quarterly, 53, pp. 537-548.

López-Jacoiste Díaz, Eugenia (2011), «El Derecho internacional y los actores no estatales en materia de seguridad: algunos planteamientos estructurales", en Javier Jordán et al. (org.), La seguridad más allá del Estado: Actores no estatales y seguridad internacional, Madrid: Plaza y Valdés, pp. 229-254.

Milanovic, Marko (2014), «UN Security Council Adopts Resolution 2178 on Foreign Terrorist Fighters", EJIL: Talk!, Blog of the European Journal of International Law. Consultado el 10.05.2015, en: http://www.ejiltalk.org/un-security-council-adoptsresolution-2178-on-foreign-terrorist-fighters/

Neumann, Peter (2015), «Foreign fighter total in Syria/Iraq now exceeds 20,000; surpasses Afghanistan conflict in the 1980s", The International Centre for the Study of Radicalisation and Political Violence Insight. Consultado el 07.05.2015, en: http://icsr.info/2015/01/foreign-fighter-total-syriairaq-now-exceeds-20000surpasses-afghanistan-conflict-1980s/

Objetivos de Desarrollo del Milenio: Informe de 2015, pp. 3-72. Consultado el 22.11.2015, en: http://www.un.org/es/millenniumgoals/pdf/2015/mdg-report-2015_ spanish.pdf

Periódico El Mundo (2015), "Interior eleva a 115 los yihadistas que han partido desde España a Irak y Siria, 40 en lo que va de año", de 23 de abril. Consultado el 12.05.2015, en: http://www.elmundo.es/espana/2015/04/23/5539301a268e3e9b3 08b456c.html

Protocolo Adicional I (1977) a los cuatros Convenios de Ginebra de 1949. Consultado el 27.07.2015, en: https://www.icrc.org/spa/resources/documents/misc/protocolo-i. htm

Reinares, Fernando (2014a), "Eclosiona el yihadismo español», Real Instituto Elcano, Opinión. Consultado el 25.04.2015, en: http://www.realinstitutoelcano.org/wps/ portal/web/rielcano_es/contenido?WCM_GLOBAL_CONTEXT=/elcano/elcano_es/ zonas_es/terrorismo+internacional/reinares-eclosiona-el-yihadismo-espanol\#. VST8L_msWSo

Reinares, Fernando (2015b), "Yihad en pos de una identidad", Real Instituto Elcano, Opinión. Consultado el 10.04.2015, en: http://www.realinstitutoelcano.org/wps/ portal/web/rielcano_es/contenido?WCM_GLOBAL_CONTEXT=/elcano/elcano_es/ zonas_es/terrorismo+internacional/reinares-yihad-en-pos-de-una-identidad\#. VSUbwvmsWSo 
Reinares, Fernando (2015c), "Yihadistas retornados, o no", Real Instituto Elcano, Opinión. Consultado el 08.05.2015, en: http://www.realinstitutoelcano.org/wps/portal/web/ rielcano_es/contenido?WCM_GLOBAL_CONTEXT=/elcano/elcano_es/zonas_es/ terrorismo+internacional/reinares-yihadistas-retornados-o-no\#.VSUEsfmsWSo

Ribeiro, Nuno (2014), "Doze jihadistas de origem portuguesa combatem na Síria e no Iraque», Periódico Público, de 2 de septiembre. Consultado el 12.05.2015, en: http://www.publico.pt/politica/noticia/doze-jihadistas-de-origem-portuguesacombatem-na-siria-e-no-iraque-1668361

Statement by the President on ISIL (2014), The White House, Office of the Press Secretary, de 10 de septiembre. Consultado el 17.04.2015, en: http://www. whitehouse.gov/the-press-office/2014/09/10/statement-president-isil-1

Strategic Comments (2014), "ISIS: the threat to homeland security", 20(7), pp. x-xi. Consultado el 13.05.2015, en: http://www.tandfonline.com/doi/

The 9/11 Commission Report (2004), pp. 1-567. Consultado el 20.11.2015, en: http:// govinfo.library.unt.edu/911/report/911Report.pdf

Whitman, Jim (2005), "Humanitarian Intervention in an Era of Pre-emptive SelfDefence", Security Dialogue, 36(3), pp. 259-274. Consultado el 24.11.2015, en: http://sdi.sagepub.com/content/36/3/259.full.pdf+html 